\title{
Benefits Analysis of Solar Low-carbon Public Buildings in Hunan District Yike Qiu ${ }^{1, a}$, Xiang Zhou ${ }^{2, b}$ \\ ${ }^{1}$ College of Civil Engineering, Hunan University, Changsha, Hunan, China \\ ${ }^{2}$ College of Civil Engineering, Hunan University, Changsha, Hunan, China \\ aqiuyikebeite@hnu.edu.cn, b1206857891@qq.com
}

Keywords: benefits analysis; solar technology; Hunan district; public buildings

Abstract. Construction is one of the three big energy consuming industries, energy efficiency in buildings has become a issues that must be considered in the sustainable development of China's economy. This paper takes the low-carbon public building as the main research object, combined with the theory of life cycle, analyzes the technology benefits of solar-thermal according to incremental cost theory. Through the information research and field survey, gathered in an office building in Hunan area information on project-related design and energy-saving technology. And the examples are given and analysed.

\section{Background and Significance}

With the development of global economic prosperity and to speed up the integration process steps, the survival of human activities to the earth's environment, climate has brought serious challenges.Construction is one of the society's three big energy consuming industries. Energy consumption of the building accounts for one-third of the total energy consumption of the whole society. Especially the large public building's electricity consumption per unit area is about 10-20 times the residential[1]. Therefore, public buildings contained huge energy saving potential to be excavated.

The core content of "Low carbon" is building which can reducing carbon dioxide emissions. At present, the generally accepted definition of the low carbon building is a building material manufacturing, building construction and operation process, increased energy efficiency, reduced fossil energy use[2].

Solar low-carbon building refers to the use of building heating, hot water, air conditioning, lighting and other functions achieve through the solar energy .

Solar technology belongs to active low carbon technology, mainly through thermal use and photovoltaic use to achieve. The thermal is mainly used for heating and cooling, The photoelectric is mainly used in solar lighting. The application of thermal technology in Chinese is very broad, with the industrialization and commercialization of a good foundation. Solar photovoltaic technology, because of its high cost, is not so popular as thermal technology.

In this paper, the study area of Hunan province is divided into central China in hot summer and cold winter zone according to the "standard of building climate zoning" (GB50178-93). And it is divided into in hot summer and cold winter area according to "civil building thermal design code" (GB50176-93). The main characteristic of the area is: warm climates, four distinct seasons; sufficient heat, rainfall concentration; Temperature is changeable in spring, summer and fall drought; The cold period is short, heat periods is long.

This paper suppresses research into economic evaluation of solar low-carbon public buildings in the whole life cycle.

\section{Comprehensive Benefit Analysis System of Solar Low-carbon Public Buildings}

In the construction industry, the building energy consumption index can be reduced through the combination of integrated solar heat utilization system and construction. This not only bring significant economic benefits for the user, can also bring huge environmental benefits for our country. Although the solar thermal utilization system compared to conventional energy systems to increase a portion of the initial investment, but the running costs of the latter is considerably less, especially current all kinds of conventional energy sources such as oil, electricity, natural gas and other, prices continue to rise, making the advantage of solar thermal systems are becoming more and more obvious. 
Today, the most common hot water system mainly consists of three types, namely, electric hot water system, gas hot water system and solar hot water system and solar hot water system installation cost to higher than the other two kinds. Especially the integration of solar energy and building design fee calculation, plus additional solar technology design fee makes investors believe that the solar water heating system cost is obviously higher than that of other hot water system. So if you need to make objective assessment of whether the solar building is economical, you should calculate the savings energy costs in its life cycle and compare it with the installation fees.

In this paper, the benefit of solar energy technology is mainly considered the relationship between the incremental benefit of the solar thermal system and the incremental cost of the initial investment.

In the course of the study, this paper has the following assumptions:

1.Suppose the maintenance costs and repair times in use period of electric hot water system and solar hot water system were exactly the same. So it does not consider the maintenance of the incremental cost of solar hot water system.

2.Suppose the energy consumption in production process of electric hot water system and solar hot water system were exactly the same.

3.Considering the uncertain factors is roughly solar thermal systems change rate of cost, discount rate, rate of change in the price of energy and energy efficiency, but in the actual project, the uncertain factors is more complex. Due to limited resources, this paper is not considered the uncertain factors one by one.

The structure of the solar low-carbon public building comprehensive benefit analysis system is shown in Figure 1:

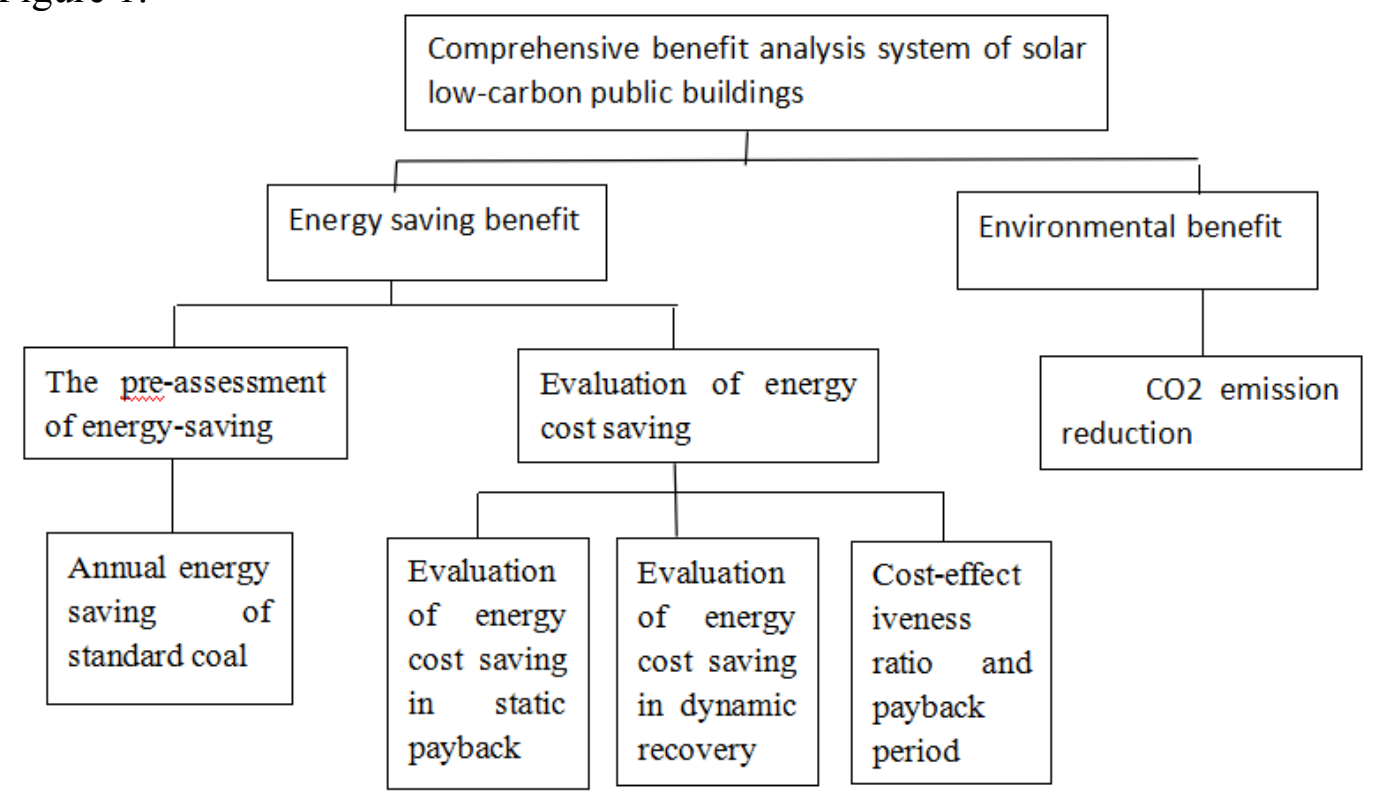

Fig. 1 Comprehensive benefit analysis system of solar low-carbon public buildings

\subsection{Energy Saving Benefit Analysis of Solar Thermal System}

According to different basis and different period, energy saving benefit analysis of solar thermal system can be divided into pre-assessment and long-term monitoring and evaluation. The study in this paper is mainly from the perspective of pre-assessment.

2.1.1 The Pre-assessment of Energy-saving

Object of pre-assessment is designed solar-thermal systems. This paper presents a pre-assessment by calculate the annual energy saving of standard coal of solar system.

Annual energy saving calculation formula of solar-thermal system:

$\Delta \mathrm{Q}_{\mathrm{save}}=\mathrm{A}_{\mathrm{C}} \mathrm{J}_{\mathrm{A}}\left(1-\eta_{\mathrm{c}}\right) \eta_{\mathrm{cd}}$

$\Delta \mathrm{Q}_{\text {save }}$ - annual energy saving of solar-thermal systems (MJ);

$\mathrm{A}_{\mathrm{C}}$ - Solar-thermal systems' hot lighting area $\left(\mathrm{m}^{2}\right)$; 
$\mathrm{J}_{\mathrm{A}}$-Each solar collector lighting on the surface of the sun irradiation total calories $\left(\mathrm{MJ} / \mathrm{m}^{2}\right)$;

$\eta_{\mathrm{c}}$-Pipeline and tank heat loss of solar-thermal system (\%);

$\eta_{\mathrm{cd}}$-Daily collection efficiency of solar-thermal system (\%)

Annual energy saving of standard coal:

$\Delta \mathrm{Q}=\Delta \mathrm{Q}_{\mathrm{save}} \times 3.4 \times 10^{-5}$

2.1.2 Evaluation of Energy Cost Saving

The evaluation of the energy saving cost of the solar thermal system can be calculated from two angles: static recovery period and dynamic recovery period.

2.1.2.1 Evaluation of Energy Cost Saving in Static Payback Period

The evaluation of the static payback period is the annual energy saving estimation, which does not take into account the cost change rate, the discount rate, the energy price change rate and the actual energy efficiency and other factors.

Calculation of annual energy cost savings

$\mathrm{P}_{\mathrm{J}}=\mathrm{C}_{\mathrm{C}} \times \Delta \mathrm{Q}_{\text {save }}$

$\mathrm{P}_{\mathrm{J}}$ - Annual energy cost savings of solar system(yuan);

$\mathrm{C}_{\mathrm{C}}$-Energy heating price that commonly used in system (yuan $/ \mathrm{MJ}$ ) (hot price = electricity /3.6);

$\Delta \mathrm{Q}_{\mathrm{save}}$-.Annual energy savings of solar system(MJ).

2.1.2.2 Evaluation of Energy Cost Saving in Dynamic Recovery Period

The evaluation of energy cost saving in dynamic recovery period is the total cost of the system in the service life, which takes into account the maintenance cost, the discount rate, the annual fuel price increases and other factors.

Calculation formula of total energy cost saving in life cycle:

$\mathrm{S}_{\mathrm{AV}}=\mathrm{P}_{\mathrm{I}}\left(\Delta \mathrm{Q}_{\text {save }} \times \mathrm{C}_{\mathrm{C}}-\mathrm{A}_{\mathrm{d}} \mathrm{D}_{\mathrm{J}}\right)-\mathrm{A}_{\mathrm{d}}$

$\mathrm{S}_{\mathrm{AV}}$ - Total cost savings of solar collector system during the whole life cycle(yuan);

$\mathrm{C}_{\mathrm{C}}$-Energy heating price that commonly used in system (yuan /MJ);

$A_{d}$-Incremental investment of solar-thermal system;

$\mathrm{D}_{\mathrm{J}}$-Annual maintenance costs associated with solar thermal systems account for the percentage of incremental investment.(\%);

$\mathrm{P}_{\mathrm{I}-\text { Discount coefficient: }} P_{I}=\frac{1}{d-e}\left[1-\left(\frac{1+e}{1+d}\right)^{n}\right](d \neq e) P_{I}=\frac{1}{1+n}(d=e)$;

$\mathrm{d}$-Annual discount rate of the market, take the bank loan rate $(\%)$;

e-Annual fuel price increase rate $(\%)$;

$\mathrm{n}$ - Life for Analysis which from the solar collector system began to run(years).

2.1.2.3 Cost-effectiveness Ratio and Payback Period

For a more comprehensive understanding of the investment in the transformation of solar-thermal system, we introduce the cost-effectiveness ratio and payback period.

(1) Cost-effectiveness ratio

Cost effectiveness analysis is to determine the project cost-effectiveness or economic rationality by comparing the expected effect and the cost of the project. Namely the ratio of the cost and the output benefit.

$R_{\mathrm{C} / \mathrm{E}}=\frac{A_{d}}{E}=\frac{3.6 \times A_{d}}{n \times \Delta Q_{\text {save }}}$

$\mathrm{R}_{\mathrm{C} / \mathrm{E}}$ - Cost-effectiveness ratio (yuan / KWh);

$\mathrm{A}_{d}$-The incremental cost of the project (yuan);

$\mathrm{E}$ - The amount of conventional fuels-substitution in the life of the application (KWh);

$\mathrm{n}$ - Service life of system(years); 
$\Delta \mathrm{Q}_{\text {save }}$-Annual energy savings of solar system(MJ);

(2) Payback period

When the solar-thermal system is running $\mathrm{n}$ years after the cost of the system is equal to the incremental cost of the system, the number of years $n$ that is the incremental cost of recycling.

$$
N=\frac{A_{d}(1+d)}{\Delta Q_{\text {save }} \cdot C c-A_{d} \mathrm{D}_{J}}
$$

$\mathrm{d}$-Annual discount rate of the market, take the bank loan rate( $\%)$;

$A_{d}$ - Incremental investment of solar-thermal system(yuan);

$\mathrm{C}_{\mathrm{C}}$-Energy heating price that commonly used in system(yuan/MJ);

$\mathrm{D}_{\mathrm{J}}$-Annual maintenance costs associated with solar thermal systems account for the percentage of incremental investment.(\%);

$\Delta \mathrm{Q}_{\text {save }}$ - Annual energy savings of solar system(MJ).

\subsection{Environmental Benefit Analysis of Solar-thermal System}

Environmental benefits assessment is a measure of the various changes in human life and production activities to the environment.

This paper analysis Environmental benefits by calculating the $\mathrm{CO} 2$ emission of solar system in the life period.

The more common way to calculate the amount of $\mathrm{CO} 2$ emissions reduction is to convert the energy saving of the system to the standard coal consumption in the whole life cycle, then convert it to the carbon content of the energy, and finally we can get the $\mathrm{CO} 2$ emission reduction of solar water heating system. The calculation is as follows:

$Q_{C Q_{2}}=\frac{\Delta Q_{\text {save }}}{W \times Z} \times F_{C Q_{2}} \times \frac{44}{12}$

$Q_{\mathrm{CQ}_{2}}-\mathrm{CO} 2$ emission of solar-thermal system in life cycle $(\mathrm{kg})$;

$\mathrm{W}$-Calorific value per kilogram of standard coal（Take $29.308 \mathrm{MJ} / \mathrm{kg}$ ）;

z-Effective efficiency of system work (\%) ;

$\mathrm{n}$-service life of system (years);

$F_{\mathrm{CQ}_{2}}$ _ Carbon emission factor ( $\mathrm{kg} / \mathrm{kg}$ of standard coal carbon).

Carbon conversion factor standard are shown in table1:

Table 1 Carbon emission factor conversion table

\begin{tabular}{ccccc}
\hline auxiliary energy & coal & electric & petroleum & $\begin{array}{l}\text { natural } \\
\text { gas }\end{array}$ \\
\hline $\begin{array}{c}\text { Carbon emission factor }(\mathrm{kg} / \mathrm{kg} \text { of } \\
\text { standard coal carbon) }\end{array}$ & 0.726 & 0.866 & 0.543 & 0.404 \\
\hline
\end{tabular}

\section{Empirical Analysis}

This paper chooses an office building project in Hunan Province as the empirical analysis object, and carries out the analysis of the economic benefits of solar energy technology.

\subsection{Project Context}

This paper adopts the method of questionnaire and on-the-spot investigation to do low carbon evaluation analysis from five perspectives of low carbon planning, low carbon design, low carbon construction, low carbon operation and low carbon resources.Finally draw the conclusion that this project belongs to the gold grade low carbon design public building, the the gold grade completed low carbon public buildings and the gold grade low carbon public buildings.

3.1.1 Project Overview

A office building project in Hunan Province is located in Loudi. The building is facing the north. It is frame structure with 10 floors on the ground and 1 floors underground. The investment amount was 74 million. The project was completed in October 2013, and was put into use in January 2014. The main technical and economic indicators of the project are shown in table 2: 
Table 2 List of technical and economic indicators of the project

\begin{tabular}{lccc}
\hline item & unit & $\begin{array}{c}\text { technical } \\
\text { index }\end{array}$ & note \\
\hline site area & $\mathrm{m}^{2}$ & 45190.2 & \\
overall floorage & $\mathrm{m}^{2}$ & 20797.81 & $\begin{array}{c}10 \text { underground 1 layer on the floor; } \\
\text { an area of } 3214.1 \mathrm{~m} \text { underground }\end{array}$ \\
$\begin{array}{c}\text { Land area of } \\
\text { road and square } \\
\text { plot ratio } \\
\text { ratio of green }\end{array}$ & $\mathrm{m}^{2}$ & 10150 & \\
space & & 0.51 & Greening area $20335 \mathrm{~m}^{2}$ \\
\hline
\end{tabular}

\subsubsection{Project Energy Saving Features in Solar Energy Technology}

In order to respond positively to the national policy of energy-saving and emission reduction, and to alleviate the pressure on the government's energy supply and construction, the office building project uses the solar energy technology in the energy saving measures:

(1) Hot water system: This system adopts the solar heating system, hot water circulation system, control system and solar plus supplementary system to achieve hot water supply.

(2) Lighting system: The outdoor lighting system uses the solar lights which convert solar energy to electric power. It saves the manpower and material resources of laying power lines, and has the effect of green environmental protection, energy saving and consumption reducing.

\subsection{Integrated Benefit Analysis of Project Solar Thermal Technology}

The projects uses 123 sets of vacuum tube collector which specifications is $58 * 1800 * 50$. According to the appendix C of GB/T 17581-1998 "vacuum tube solar collector", the reference area of the instantaneous efficiency calculation of the vacuum tube solar collector, the collector area of each level is $6.5 \mathrm{~m}^{2}$. The total area of the solar collector used in the project is $123 * 6.5=799.5 \mathrm{~m}^{2}$.

\subsubsection{Energy Saving Benefit Analysis of Solar Thermal System}

This paper will analyze the energy efficiency of the project from two aspects: the pre-assessment of energy saving and the cost of energy efficiency.

3.2.1.1 The Pre-assessment of Energy-saving

According to the formula (1), Ac takes $799.5 \mathrm{~m}^{2}$. And the solar radiation resources in Loudi is relatively rich, so value of $\mathrm{J}_{\mathrm{A}}$ is $4039.3 \mathrm{MJ} / \mathrm{m}^{2}$. $\eta_{\mathrm{cd}}$ is $50 \%$ and $\eta_{\mathrm{c}}$ is $13 \%$. We can get annual energy saving of solar-thermal system:

$$
\Delta \mathrm{Q}_{\mathrm{save}}=\mathrm{A}_{\mathrm{C}} \mathrm{J}_{\mathrm{A}}\left(1-\eta_{\mathrm{c}}\right) \eta_{\mathrm{cd}}=799.5 * 4039.3 *(1-13 \%) * 50 \%=1404797.9 \mathrm{MJ}
$$

According to the formula (2), annual energy saving of standard coal is:

$\Delta \mathrm{Q}=\Delta \mathrm{Q}_{\mathrm{save}} \times 3.4 \times 10^{-5}=1404797.9 * 3.4 * 10^{-5}=49.23$ (ton)

\subsubsection{Evaluation of Energy Cost Saving}

(1) Energy cost saving in static payback period

Set electric heating equipment efficiency is $95 \%$ and the electricity price is 0.6 yuan $/ \mathrm{kWh}$, then we can get $\mathrm{Cc}=0.18 / \mathrm{MJ}$. According to the formula (3), annual energy cost saving is:

$\mathrm{P}_{\mathrm{J}}=\mathrm{C}_{\mathrm{C}} \times \Delta \mathrm{Q}_{\text {save }}=0.18 * 1404797.9=252863.6$ (yuan)

(2) Total Energy Cost Saving in Dynamic Payback Period of the Life Cycle

Compared with the general electric hot water system, the total investment is 1544310 yuan. Maintenance costs accounted for $1 \%$ of the total increase in investment, bank lending rate is $6.55 \%$, the annual rate of fuel prices by $1 \%$ to consider, the system of service life is set to 15 years.

It is calculated that the discount coefficient of dynamic recovery period PI is 9.67.

According to the formula (4), we can get the total energy cost saving of 15 years is:

$\mathrm{S}_{\mathrm{AV}}=\mathrm{P}_{\mathrm{I}}\left(\Delta \mathrm{Q}_{\text {save }} \times \mathrm{C}_{\mathrm{C}}-\mathrm{A}_{\mathrm{d}} \mathrm{D}_{\mathrm{J}}\right)-\mathrm{A}_{\mathrm{d}}=9.67 \times(252863.6-1544310 \times 1 \%)-1544310=751546.2($ yuan $)$ 


\subsubsection{Cost-effectiveness Ratio and Payback Period}

(1) Cost-effectiveness ratio

According to the formula (5), we can get the cost-effectiveness ratio of the solar thermal system compared with the general electric hot water system:

$$
R_{\mathrm{C} / \mathrm{E}}=\frac{A_{d}}{E}=\frac{3.6 \times A_{d}}{n \times \Delta Q_{\text {save }}}=\frac{3.6 \times 1544310}{1404797.9 \times 15}=0.26
$$

(yuan / KWh)

(2) Payback Period

According to the formula (6), we can get the incremental cost payback period for solar solar thermal system is:

$$
N=\frac{A_{d}(1+d)}{\Delta Q_{\text {save }} \cdot C c-A_{d} \mathrm{D}_{J}}=\frac{154431 \times(1+6.55 \%)}{1404797.9 \times 0.18-1544310 \times 1 \%} \approx 7 \quad \text { (years) }
$$

3.2.2 Environmental Benefit Analysis of Project Solar Thermal System we can get the result according to the formula (7):

If the project uses electric hot water system, then

$$
Q_{C Q_{2}}=\frac{1404797.9}{29.3 \times 87 \%} \times 0.866 \times \frac{44}{12}=175 \text { (ton) }
$$

If the project uses gas hot water system, then

$$
Q_{\mathrm{CQ}_{2}}=\frac{1404797.9}{29.3 \times 87 \%} \times 0.404 \times \frac{44}{12}=81.64 \text { (ton) }
$$

The system annual energy saving equivalent to 49.23 tons of standard coal, the market price of 900 yuan / ton, so the cost saving equivalent to 44307 yuan per year.Compared with the electric hot water system and gas hot water system, the annual reduction of carbon dioxide emissions were 175 tons and 81.64 tons. Solar-thermal technology of projects not only bring huge economic benefits and social benefits, but also for the country's energy saving and emission reduction has made a contribution.

\section{Conclusions}

The study found that solar thermal system not only has such great benefits, also bring considerable environmental benefits. Thus, solar low-carbon energy saving technology plays an important role for the development and popularization of building low-carbon. The development and popularization of solar low-carbon energy technology will greatly promote the construction of low-carbon economy in China in the process.

If there are conditions, should be combined with the relevant LCA life cycle software, energy consumption software to account for accurate carbon emissions. With the real data, the problem can be described more intuitively, it is only able to make low carbon is no longer just stay in the concept and theory.

\section{References}

[1] Robert GH, EF William. LCA How it came about: Personal reflections on the origin and the development of LCA in the USA [J]. Int.J.LCA, 1996(1):4-7

[2] Bribian, Uson, Scarpellini. Life cycle assessment in buildings: State-of-the-art and simplified LCA methodology as a complement for building certification. Building and Environment, 2009, 44(12):2510-2520

[3] Steve Sorrell. Making the Link: Climate Policy and the Reform of the UK Construction Industry [J].Energy Policy, 2003, (09):865-878

[4] Stem N. The Economics of Climate Change [J]. The Stem Review, 2007, (04):34-43 
[5] Skea. Jim. Cold Comfort in a high Carbon Society [J]. Building Research and Information, 2009, (01):74-78

[6] Tuohy Paul, Roaf Sue. Twenty First Century Standards for Thermal Comfort: Fostering Low-carbon Building Design and Operation [J]. Architectural Science Revies, 2010, (01):78-86

[7] C. A. Kennedy, N. Ibrahim, D. Hoornweg. Low-carbon infrastructure strategies for cities [J]. Nature Climate Change, 2014, (3):89-96 